\title{
Joining metrics enhancement when combining FSW and ball-burnishing in a 2050 aluminium alloy
}

\author{
A.J. Sánchez Egea ${ }^{\text {a, b, }}$ *, A. Rodríguez 1, D. Celentano ${ }^{b}$, A. Calleja ${ }^{c}$, L.N. López de Lacalle ${ }^{a}$

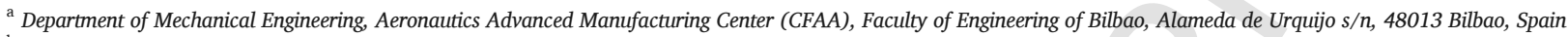 \\ ${ }^{\mathrm{b}}$ Department of Mechanical and Metallurgical Engineering, Pontificia Universidad Católica de Chile, Av. Vicuña Mackenna 4860, 7820436 Region Metropolitana, Chile \\ ${ }^{\mathrm{c}}$ Department of Mechanical Engineering, Faculty of Engineering of Vitoria-Gasteiz, Nieves Cano, 12, 01006 Vitoria-Gasteiz, Spain
}

\section{ART ICLE INFO}

\section{Keywords:}

Friction stir welding

Ball-burnishing

Surface roughness

Microhardness

Residual stress

\begin{abstract}
A B S T R A C T
This report describes the effect of the ball-burnishing process on the mechanical properties of 2050 aluminium alloy that was previously friction stir welded. This process is a fast, environmentally-friendly and cost-effective surface treatment based on the plastic deformation of the surface irregularities. Consequently, residual stress, material hardening and micro-structural alterations are investigated to improve fatigue strength and wear resistance. The results show that the ball-burnishing treatment enhances the surface properties by increasing the material hardness about $37.5 \%$ and by decreasing the average surface roughness from $2.23 \mu \mathrm{m}$ to $0.06 \mu \mathrm{m}$ when a high pressure and a perpendicular burnishing is deployed. Additionally, in-depth compressive residual stresses are generated from $-315 \mathrm{MPa}$ to $-700 \mathrm{MPa}$ depending on the burnishing configuration. Finally, a numerical simulation of the material elastoplastic response is performed to analyze the residual stress continuity in the cross sectional area when using two radial feeds and burnishing pressures. In short, the present study helps to reduce time consumption by selecting the larger radial feed combined with a proper burnishing pressure to ensure the desired quality and compressive residual stress at the surface, which are indices of enhancing the fatigue strength at the nugget zone of the welded area.
\end{abstract}

\section{Introduction}

Engineers today are facing the challenge to join materials with novel technologies to reduce the drawbacks associated to the thermal impact in the material microstructure [1]. Some of these drawbacks are the porosity formation, solidification cracking and the chemical reaction that may arise during fusion welding of materials. An efficient welding process is achieved when special attention is devoted to the joint design and preparation, the operation parameters (feed rate, output energy, thermal gradient, ...) and the utilized metallic alloys [2]. However, most of the conventional fusion welding techniques used to join superalloys often have some defects, such as liquation induced cracking and porosity, developed as a consequence of entrapped hydrogen inside of the weld bead during solidification [3]. Besides, the formation of various types of intermetallic compounds in the weld zone undermines the weld integrity. For these reasons, many alternative welding practices have been studied and developed, in order to obtain defect-free joining of light alloys. The problems to perform an effective join between metallic sheets of light alloys, which are difficult to obtain by employing commonly used technologies, have led to a widespread use of new techniques of welding. Lohwasser and Chen [4] reported in detail the Friction Stir Welding (FSW) process for metallic alloys used in diverse industrial fields, such us aeronautics, aerospace and automotive. This novel welding technique with a high degree of innovation promotes an environmentally friendly manufacturing process. Besides, the implementation of these sustainable and environment friendly manufacturing processes meets with the current requirements of the roadmap of Horizon 2020 [5] and the market regarding the productivity, energy and ecological efficiency. A recent study of Cojocaru et al. [6] described the possibility of joining dissimilar materials by FSW and its potential to be implemented in a real industrial environment. Operational parameters have been proposed to join dissimilar materials with different thickness using two types of technologies, i.e., FSW and FSW-TIG, with the aim of facing real automotive production drawbacks.

Much research has been published to improve the mechanical and surface properties after the welding process. To this end, the ball-burnishing technique is a potential solution that can enhance the surface properties by deforming the welding area that commonly presents different thermomechanical affected

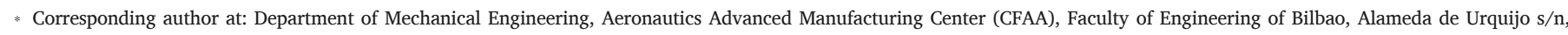
48013 Bilbao, Spain.

Email addresses: antonio.egea@ehu.eus, antonio.egea@ing.puc.cl (A.J.Sánchez Egea); adrian.rodriguez@ehu.eus (A. Rodríguez); dcelentano@ing.puc.cl (D. Celentano); amaia.calleja@ ehu.eus (A. Calleja); norberto.lzlacalle@ehu.eus (L.N.López de Lacalle) 
zones. In particular, Prevey et al. [7] investigated the fatigue improvement of aluminium alloys firstly welded by FSW and later low plasticity burnished as a final surface treatment. They stated that the burnishing process induces compression residual stresses which tend to improve the fatigue behavior of the component. Furthermore, the application of deformation treatments on welded aluminium components was investigated by Huang et al. [8] who developed a special design of a burnishing tool to be used at the same time than the FSW process, resulting a novel technique denominated as "In Situ Rolling Friction Stir Welding". Moreover, Lacalle and coworkers [9] described the influence of the burnishing process on the surface properties of an aeronautic alloy (Inconel 718) using different burnishing parameters to obtain the desired final roughness. They found out that higher pressure promotes the appearance of grooves on the surface due to the ductility of this alloy. Furthermore, a mirror-like surface is achieved when a burnishing process is applied, although better surface quality is denoted when a perpendicular strategy to the milling direction combined with a smaller radial width burnishing configuration is selected. In another study [10], they also described this surface treatment on different metallic materials commonly used in molds with the aim of comparing time consumption with respect to other manufacturing surface applications. The results that they provided stated that the production time for the finishing operation can be reduced when using burnishing instead of a milling machine since the velocities in these two processes are about $15 \mathrm{~m} / \mathrm{min}$ and within the range of $1-2 \mathrm{~m} / \mathrm{min}$, respectively.

According to these results, the burnishing process was found to improve the surface properties by reducing the surface roughness and increasing the material hardness. Therefore, it is considered as an interesting technology to reinforce the strength of the welding area that has suffered a thermal softening due to the FSW process. To this end, the aim of the present work is to investigate the enhancement of the surface properties considering a combination of two strategies (parallel and perpendicular) and two operational parameters (radial feed and pressure) when using ball-burnishing treatment in previously FSWed aluminium alloys. Additionally, the residual stresses are estimated when using different burnishing configurations to assess the stress distribution continuity in the transversal section plane. The potential benefits of using these combined manufacturing processes are twofold: to reduce time consumption by selecting the larger radial feed combined with a proper burnishing pressure and to ensure the desired quality and compressive residual stress at the surface which is an index of enhancing the fatigue strength at the nugget zone (NZ) of the welded area.

\section{Methodology}

Commercial 2050 aluminium alloy with thermal treatments T8 (artificially aged) and T3 (naturally aged) were tested in this work. This material

$$
\text { is }
$$
com- monly used by Airbus in their aircraft models A350-800 and A350-800F, particularly for the inferior structures of some wing components. Accordingly, Table 1 shows the chemical composition and the main mechanical properties of this alloy.

The FSW and the ball-burnishing processes were performed with a 3-axis machining center (model: Kondia HS1000). A burnishing tool (Ecoroll model: HG6-19E90-ZS20-X) and a high pressure pump and a $6 \mathrm{~mm}$ diameter silicon nitride ceramic ball were utilized to combine different burnishing strategies and pressure. In this sense, the optimal configuration is determined to enhance the surface properties of the nugget zone (NZ). FSW parameters for these alloys were in the usual application range [11,12], where the rotational speed was within the range of 700 to $1000 \mathrm{rpm}$, the traverse speed was between 100 and $200 \mathrm{~mm} /$ min and a tilt angle was between $2^{\circ}$ and $3^{\circ}$. In order to find the optimal burnishing operational conditions, several preliminary experiments were performed to assess a proper surface treatment in the as-received alloy. To this end, the combination of four pressures and six radial feeds were studied with the aim to find an acceptable surface quality. All the experiments were carried out with a feed rate of $7.5 \mathrm{~m} / \mathrm{min}$. Table $2 \mathrm{ex}-$ hibits the preliminary ball-burnishing parameters used to increase the surface quality.

The lowest surface roughness values were obtained with pressures of $10 \mathrm{MPa}$ and a radial feed of $0.1 \mathrm{~mm}$, whereas the worst surface roughness was found when combining $40 \mathrm{MPa}$ of pressure and $0.5 \mathrm{~mm}$ of radial feed. For a pressure of burnishing of $40 \mathrm{MPa}$ and radial pass width smaller than $0.2 \mathrm{~mm}$, the surface had excessively deformed by generating large surface irregularities. The surface roughness marked with red squares defines the four burnishing configurations $0.05 \mathrm{~mm}$ and $0.3 \mathrm{~mm}$ of radial feed and $10 \mathrm{MPa}$ and $30 \mathrm{MPa}$ of burnishing pressures) chosen to investigate how they affect the welding area by FSW, particularly the NZ of the aluminium alloy treated with two types of thermal treatments (T8 and T3). Additionally, two burnishing strategies, parallel and perpendicular, were carried out to analyze if combined with the aforementioned parameters improve the surface properties of the welded specimens. Then, a microhardness tester (Future-Tech model: FM-800) was used to estimate the increase of the material hardness with respect to the different burnishing configurations used. A total of 3 measurements were recorded to obtain the average values. The calibration of this equipment ensures accuracy according to international standards ASTM E-384, and ISO 6507-2. A confocal 3D profilometer (Leica model: DCM-3D) was used to assess the improvement of the surface roughness. Several measurements have been done in the same region to avoid large dispersions, where the measurements resolution was $0.1 \mathrm{~nm}$. In this sense, the priority is to get similar physical properties in the welded zone and in the base material. In particular, the priority feature to improve is the surface and sub-surface hardness in the NZ of the welding area. Therefore, the burnishing pressure must be as high as possible to prevent the generation of defects on

Table 1

Chemical composition and mechanical properties of 2050 aluminium alloy.

\begin{tabular}{|c|c|c|c|c|c|c|c|c|}
\hline Composition & $\% \mathrm{Fe}$ & $\% \mathrm{Cu}$ & $\% \mathrm{Mn}$ & $\% \mathrm{Mg}$ & $\% \mathrm{Zn}$ & $\% \mathrm{Li}$ & $\% \mathrm{Ag}$ & $\% \mathrm{Zr}$ \\
\hline & $0.08 \quad 0.10$ & $3.2-3.9$ & $0.2-0.5$ & $0.2-0.6$ & 0.25 & $0.7-1.7$ & $0.2-0.7$ & $0.06-0.14$ \\
\hline Properties & $\begin{array}{l}\mathrm{K}_{\mathrm{IC}} \\
\left(\mathrm{Mpa} \cdot \mathrm{m}^{\wedge} 1 / 2\right) \\
\sim 37\end{array}$ & $\begin{array}{l}\text { Elong. } \\
(\%) \\
\sim 11\end{array}$ & & $\begin{array}{l}\text { Yield stress } \\
\text { (MPa) } \\
\sim 500\end{array}$ & & $\begin{array}{l}\mathrm{E} \\
(\mathrm{GPa}) \\
\sim 77\end{array}$ & & $\begin{array}{l}\text { UTS } \\
(\mathrm{MPa}) \\
\sim 530\end{array}$ \\
\hline
\end{tabular}

Table 2

Average surface roughness when using different burnishing configuration in 2050 aluminium alloy.

\begin{tabular}{|c|c|c|c|c|c|}
\hline & \multirow{2}{*}{ Radial feed (mm) } & \multicolumn{4}{|c|}{ Pressure (MPa) } \\
\hline & & 10 & 20 & 30 & 40 \\
\hline \multirow{4}{*}{ As-received $(\mu \mathrm{m})$} & - & & \multicolumn{2}{|c|}{0.47} & \\
\hline & 0.05 & 0.23 & 0.26 & 0.36 & - \\
\hline & 0.1 & 0.2 & 0.28 & 0.31 & - \\
\hline & 0.2 & 0.32 & 0.53 & 0.71 & 1.02 \\
\hline \multirow{3}{*}{ Burnishing $(\mu \mathrm{m})$} & 0.3 & 0.61 & 0.95 & 0.98 & 1.51 \\
\hline & 0.4 & 0.93 & 1.43 & 1.87 & 2.14 \\
\hline & 0.5 & 1.96 & 2.54 & 3.22 & 3.76 \\
\hline
\end{tabular}


the surface. Fig. 1 exhibits the surface profile of the selected ball-burnishing configurations in 2050 aluminium alloys FSWed.

Finally, the residual stresses in the specimens were measured by the hole drilling method (model: Vishay 8) following the standard ASTM E837. A total of three measurements per each configuration were performed to determine the average value. A schematic diagram of the ball-burnishing process of previously FSWed aluminium specimens is presented in Fig. 2. The figure also exhibits the two burnishing strategies and the three metallographic zones (nugget zone, thermomechanical affected zone and heat affected zone) due to the welding process.

\section{Results and discussion}

The methodology of this work is divided in four subsections: surfaces material hardness, surface roughness, residual stresses and numerical approximation. Therefore, throughout this section the main findings and limitations of using different strategies and operational parameters of ball-burnishing process in previously FSWed alloys are explained.

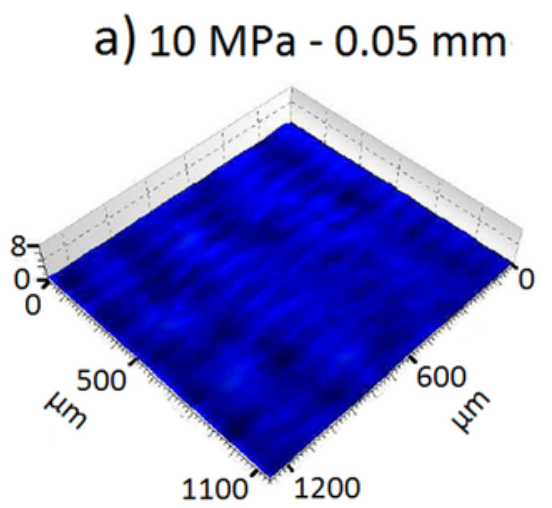

\section{b) $30 \mathrm{MPa}-0.05 \mathrm{~mm}$}

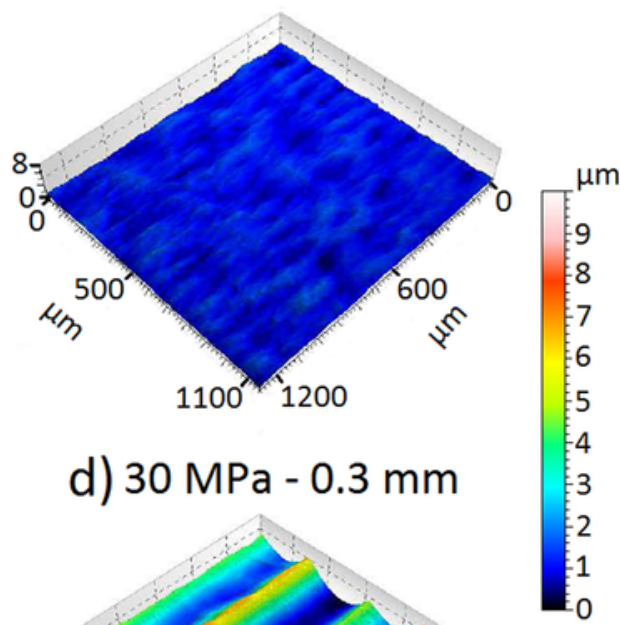

c) $10 \mathrm{MPa}-0.3 \mathrm{~mm}$
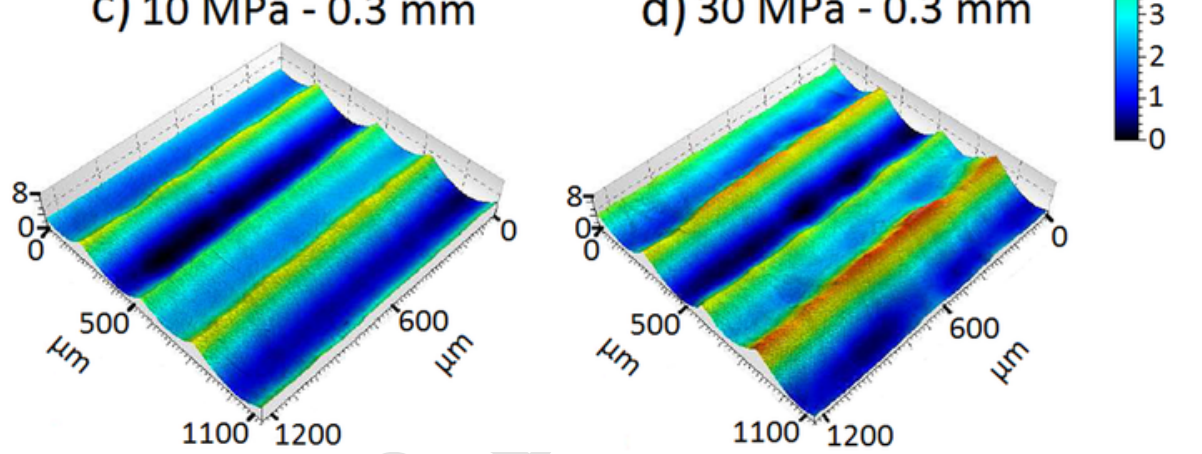

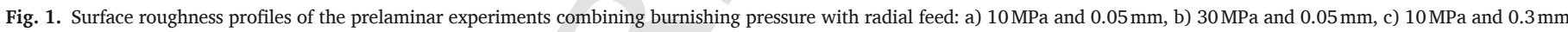
and d) $30 \mathrm{MPa}$ and $0.3 \mathrm{~mm}$.

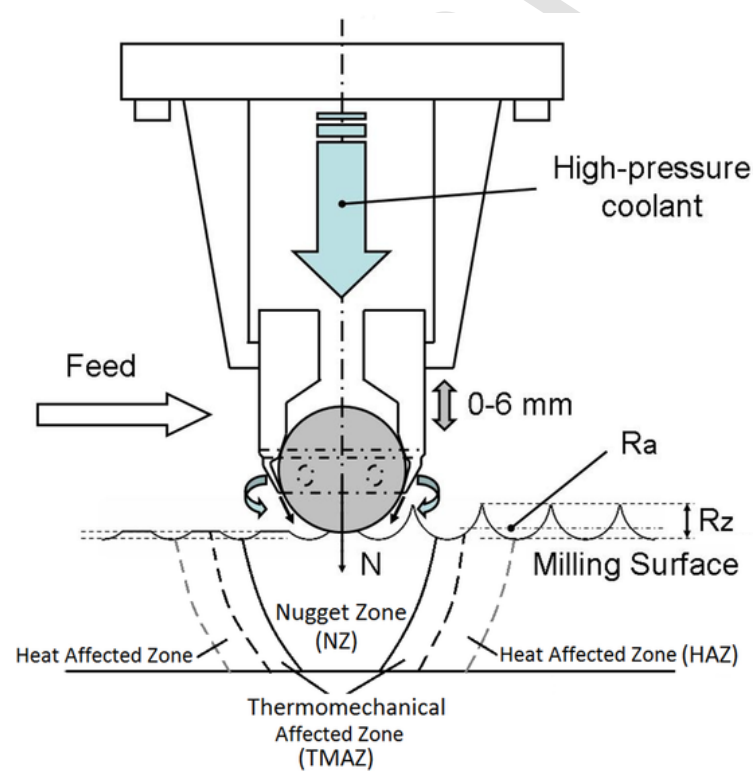

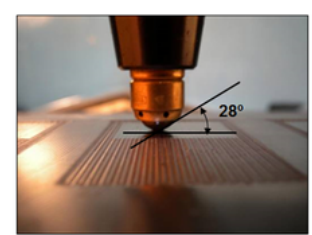

Ball-burnishing strategies

Parallel direction Perpendicular direction
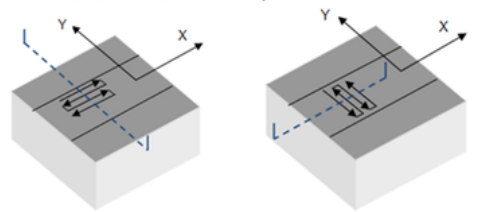

Metalographic observation welded zone
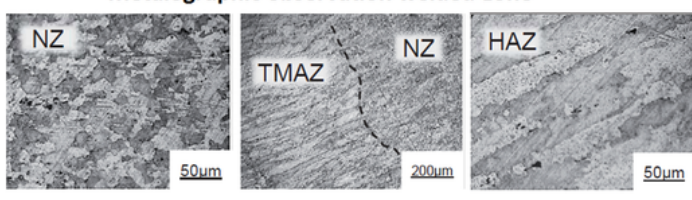

Fig. 2. Outline of the ball-burnishing process combining different strategies and configurations in aluminium alloys previously FSWed. 


\subsection{Surfaces and in-depth material hardness}

The surface and in-depth values of hardness are measured along the transversal section of the welded zone. In particular, the measurement distribution is localized in the NZ of the welded specimen with different surface treated configurations. Fig. 3 shows the microhardness through the NZ of the welded aluminium alloy for the heat treatment T8 before and after the FSW + Burnishing processes. Additionally, it is shown the influence of the operational parameters (radial feed and pressure) and two burnishing strategies (parallel and perpendicular) on the material hardness in the aluminium alloy.

The curves represent the surface material hardness of the transversal section of the welding area, where the center of the NZ is the initial reference. Therefore, the hardness distribution of FSW and FSW + Burnishing with respect to the distance of the center of the NZ at the surface (dashed red line of the right-hand side) is shown for each case. Fig. 3a shows the curves with the thermal treatment T8 before the FSW and burnishing processes that exhibits lower values of hardness in the welding area and higher values at the specimen area not affected by the temperature during the FSW process. Whereas, the curves of Fig. 3b exhibits similar values of material hardness for the welded and the non-welded areas, due to the thermal softening applied in the thermal treatment T8 after the FSW operation. According to this, the hardness decrease about $40 \%$ in the welding area due to the thermal impact, which corresponds to the noticeable change from $170 \mathrm{HV}$ to $100 \mathrm{HV}$ at the distance range of $17-30 \mathrm{~mm}$ from the center of the NZ. On the other hand, the burnishing process increases the surface hardness and, consequently, reduces the hardness difference between the welding area and the as-received specimens that have not been thermally affected. In particular, hardness values of $180 \mathrm{HV}$ are observed in the non-welded area and values of $150 \mathrm{HV}$ in average are measured in the welded zone. The hardness drop is estimated to be around 10 to $20 \%$ depending on the used operational burnishing parameters, whereas the best scenario is denoted for $30 \mathrm{MPa}$ of pressure and $0.05 \mathrm{~mm}$ of radial width. For this configuration, the hardness values are found to be $160 \mathrm{HV}$, which is quite similar to the $170 \mathrm{HV}$ of the specimen area not affected by the welding process. According to the aforementioned results, the burnishing process primarily affects the welded area where the specimen shows a lower hardness and, subsequently, is more susceptible to be plastically deformed. Additionally, the pressure is found to have an influence on the hardness enhancement, while the radial feed does not show significant differences in the hardness results.

After the surface hardness measurements, the in-depth values of hardness are measured and plotted in Fig. 4. Due to the previous results, only the hardness values for $10 \mathrm{MPa}$ and $30 \mathrm{MPa}$ pressures are measured, when using a $0.3 \mathrm{~mm}$ of radial feed and a perpendicular burnishing strategy. These hardness values are taken along the NZ and compared with the hardness values of the FSWed specimen (dashed red line) in the same welding region.

Fig. 4a and $\mathrm{b}$ show the in-depth hardness values that depend considerably on the burnishing pressure, e.g., for $10 \mathrm{MPa}$, a layer up to $0.5 \mathrm{~mm}$ thickness has been strengthened while for $30 \mathrm{MPa}$, a layer up to $1 \mathrm{~mm}$ thickness has been strengthened, as shown in Fig. 4c. Moreover, the bigger hardness difference between the two pressure conditions is found at $0.3 \mathrm{~mm}$ from the surface, where the higher pressure shows a hardness value of $21.5 \%$ higher than that of the lower pressure configuration. The burnishing configuration of $10 \mathrm{MPa}$ exhibits a similar hardness value to that of the reference configuration when the in-depth distance reaches $0.75 \mathrm{~mm}$, whereas the burnishing configuration of $30 \mathrm{MPa}$ reaches similar values to those of the reference at the in-depth distance of $1.2 \mathrm{~mm}$. Beyond the $1.25 \mathrm{~mm}$ of depth, the hardness values are similar to those of the reference independently of the brushing pressure.

\subsection{Surface roughness}

Plastic deformation generated by the burnishing process causes roughness peaks flows toward the valleys, which promote the formation of a new surface topography. The appearance of the final surface becomes a combination of the previously machined one and the effect of the burnishing. The final roughness is influenced by the burnishing pressure, the radial width and the material mechanical properties. Although the burnishing speed does not have a significant influence on the surface roughness, it is a crucial parameter in reducing the time to finish the specimen, as stated in a similar work by Rodriguez et al. [13]. Table 3 shows the obtained surface roughness values in the burnishing tests. The surface roughness values were obtained in the perpendicular direction to the burnishing direction.
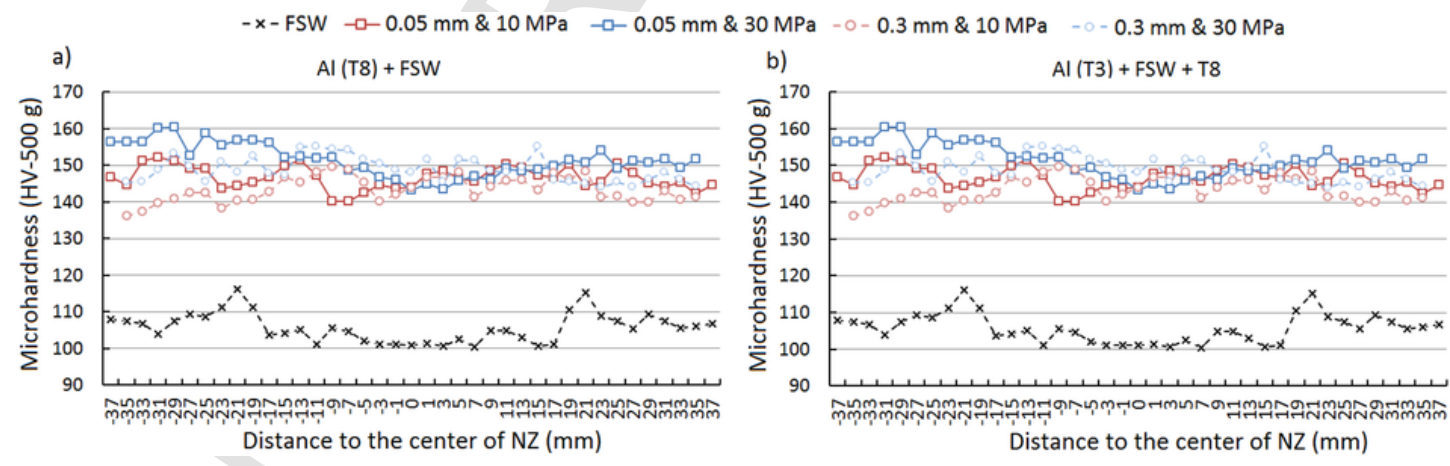

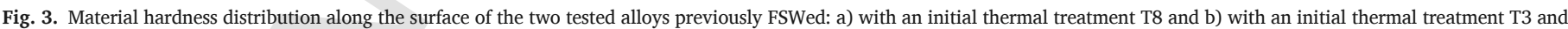
final thermal treatment T8.

a)

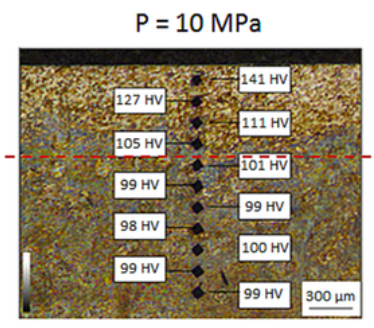

b)

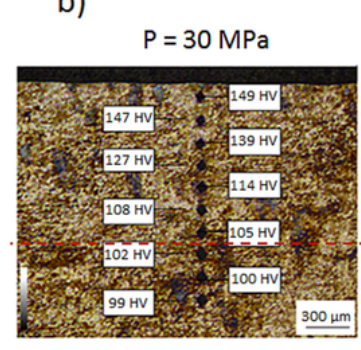

c)

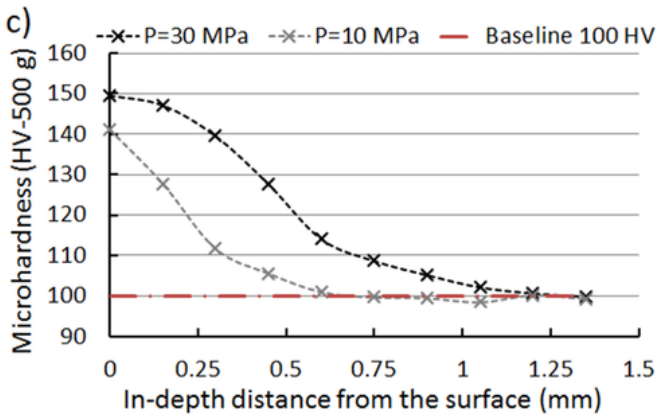

Fig. 4. In-depth material hardness when using a two ball-burnishing pressures: a) $10 \mathrm{MPa}, \mathrm{b}) 30 \mathrm{MPa}$ and c) the hardness distribution respect to the base line. 
Table 3

Surface roughness values ( $\mathrm{Ra}$ and $\mathrm{Rz}$ ) when comparing parallel and perpendicular burnishing strategies at the NZ.

\begin{tabular}{|c|c|c|c|c|c|c|c|c|c|c|c|}
\hline \multirow{2}{*}{$\begin{array}{l}\text { Parameters } \\
\text { Radial feed }\end{array}$} & \multicolumn{4}{|c|}{$\mathrm{Al}(\mathrm{T} 8)+\mathrm{FSW}$} & \multicolumn{4}{|c|}{$\mathrm{Al}(\mathrm{T} 3)+\mathrm{FSW}+\mathrm{T} 8$} & \multicolumn{3}{|c|}{ Milled nugget zone } \\
\hline & Pressure & $\perp$ & & $\|$ & & $\perp$ & & $\|$ & & & \\
\hline$(\mathrm{mm})$ & (MPa) & $\mathrm{R}_{\mathrm{a}}$ & $\mathrm{R}_{\mathrm{z}}$ & $\mathrm{R}_{\mathrm{a}}$ & $\mathrm{R}_{\mathrm{z}}$ & $\mathrm{R}_{\mathrm{a}}$ & $\mathrm{R}_{\mathrm{z}}$ & $\mathrm{R}_{\mathrm{a}}$ & $\mathrm{R}_{\mathrm{z}}$ & $\mathrm{R}_{\mathrm{a}}$ & $\mathrm{R}_{\mathrm{z}}$ \\
\hline \multirow[t]{2}{*}{0.05} & 10 & 0.08 & 0.33 & 0.08 & 0.56 & 0.06 & 0.31 & 0.1 & 0.67 & 0.23 & 2.08 \\
\hline & 30 & 0.14 & 0.68 & 0.18 & 0.97 & 0.24 & 1.59 & 0.16 & 1.13 & & \\
\hline \multirow[t]{2}{*}{0.3} & 10 & 1 & 4.54 & 1.08 & 4.84 & 1.14 & 5.05 & 1.01 & 4.43 & & \\
\hline & 30 & 1.4 & 6.45 & 1.91 & 8.31 & 2 & 8.09 & 2.04 & 9.05 & & \\
\hline
\end{tabular}

*All values are expressed in $\mu \mathrm{m}$ if the unit is not explicit denoted. The measurement resolution is $0.1 \mathrm{~nm}$.

As it is expected for lower radial feeds combined with lower values of pressure, a smaller average surface roughness is obtained. Additionally, perpendicular burnishing strategies exhibit, in general, lower surface roughness values than those of the parallel strategy. The thermal treatment T8 after the FSW process seems to generate worse surface quality, especially if high pressure is used to burnish the surface. The machined specimens present similar values than those obtained with the combination of low radial feed and pressure with a parallel burnishing strategy and a thermal treatment after the FSW process. It is seen that the thermal treatment after the FSW process makes the material too soft and, consequently, the burnishing operation promotes a higher surface roughness compared with a pre-stress material matrix (Al (T8) + FSW). Therefore, the highest average surface roughness $(2.04 \mu \mathrm{m})$ is listed for higher values of feed and pressure with a parallel strategy and thermal treatment after the FSW process, whereas the best surface quality $(0.08 \mu \mathrm{m}$ of $\mathrm{Ra})$ is found for the opposite configuration, i.e., the lowest values of feed and pressure with a perpendicular strategy and thermal treatment before the FSW process. Comparable results have been recently reported by Nestler and Schubert [14] when studying the rolling burnishing process of an aluminium alloy with silicium carbide (SiC) embedded particles. They described how the surface roughness increases when large radial feeds and burnishing forces are used. However, they reported a better surface quality when large burnishing forces are applied, mainly because the material hardness of the alloys is higher than the one studied here due to the amount of SiC particles. The milling and burnishing processes are shown Fig. 5 with the aim of comparing the surface quality in both processes. As it is shown, the burnished surface treatment exhibits a mirror-like finishing surface.

\subsection{Surface and in-depth residual stress distributions}

Plastic deformation produced on the part surface during ball burnishing causes a significant alteration of the residual stress state. In particular, the ball burnishing induces compressive residual stress on the surface layer which prevents crack initiation and thus improves the fatigue strength and corrosion resistance of the material. The present work exhibits the residual stress evolution in the surface and through $1 \mathrm{~mm}$ depth in the NZ for all the burnishing configurations. Firstly, Fig. 6a shows the maximum surface values of the compressive
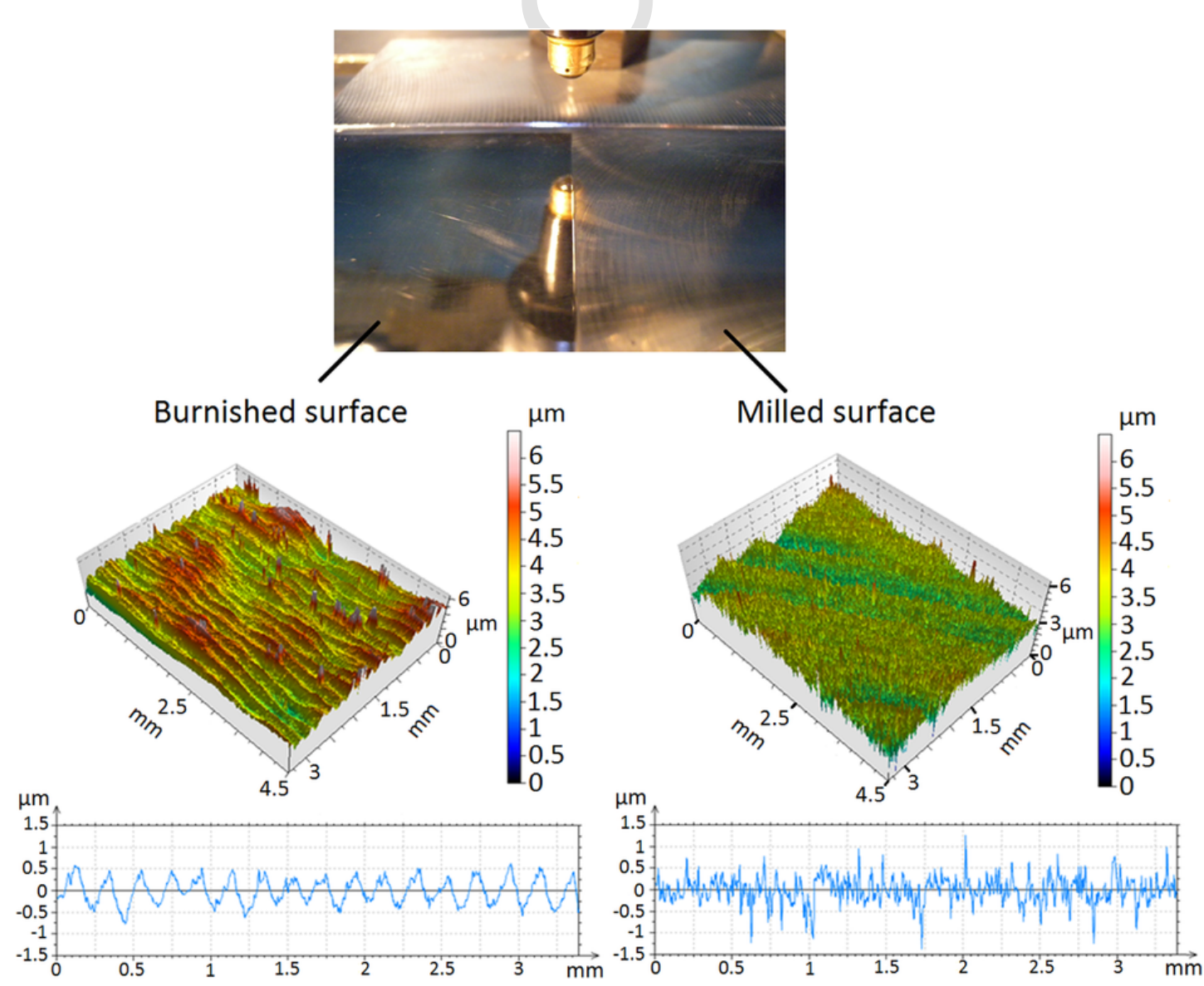

Fig. 5. Surface roughness of a ball-burnishing treatment and a milled operation. 
a)

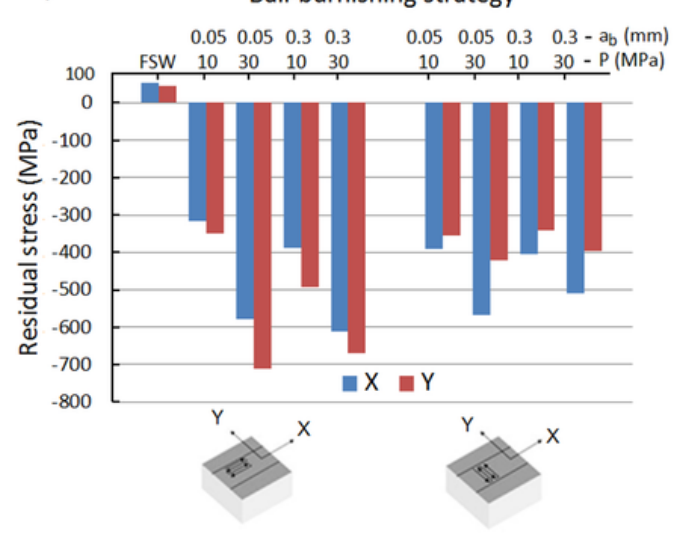

b)

In-depth distance from the surface $(\mathrm{mm})$

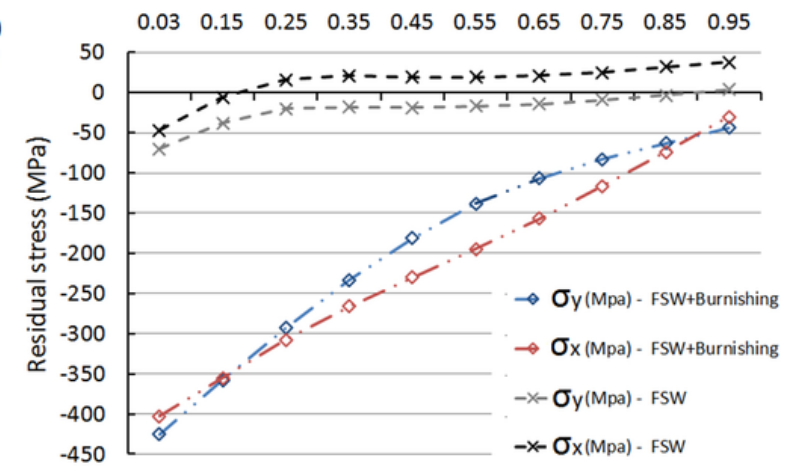

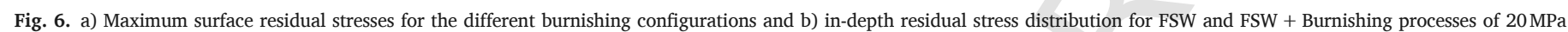
and $0.1 \mathrm{~mm}$ and perpendicular strategy to the welding direction.

residual stresses at the $\mathrm{NZ}$ in order to compare the different strategies and operational parameters. Subsequently, Fig. $6 \mathrm{~b}$ presents the in-depth values of compressive residual stresses distribution to determine and compare the ball-burnishing strategy with respect to the as-received FSWed alloys.

The surface residual stresses denote that the as-received FSWed specimens exhibit expansive stresses of about $50 \mathrm{MPa}$ independently of the measurement direction. As expected, a higher burnishing pressure promotes higher compressive residual stresses, whereas the radial feed does not show an obvious trend. Looking at the burnishing strategies in Fig. 6a, parallel configurations combined with higher pressure exhibit the higher compressive stresses independently of the used radial feed, whereas the same parallel strategy configuration combined with smaller pressure and radial feed exhibits the lowest compressive stresses oriented along the welding direction. Furthermore, the maximum compressive residual stresses are found to be higher in the perpendicular direction to the burnishing trajectory. In particular, the in-depth stresses denote that the combination of FSW and ball-burnishing treatment promotes large com- pressive residual stress up to $-400 \mathrm{MPa}$ near the surface and about $-200 \mathrm{MPa}$ for $0.5 \mathrm{~mm}$ of depth, as shown in Fig. $6 \mathrm{~b}$. For depth values higher than $1 \mathrm{~mm}$, no differences are found between the burnishing configurations and the FSWed as-received specimens. Similar residual compression values are reported by Scheel et al. [15], when they studied the influence of the surface treatment using shot-peening and ball-burnishing on the 7075 aluminium alloy with a thermal treatment T6. Fig. 7 presents the in-depth compressive residual stresses distribution for the different brushing configurations applied in the FSWed aluminium alloy with a thermal treatment T8. This figure represents four configurations: two burnishing configurations, parallel (Fig. 7a and c) and perpendicular (Fig. 7b and d) with respect to the welding direction, and two measurement directions, parallel (Fig. 7a and b) and perpendicular to the welding direction (Fig. 7c and d).

The residual stress distributions present similar trends independently of the burnishing strategy with respect to the welding direction and the measurement direction. Higher values of residual stresses are found when a parallel burnish-

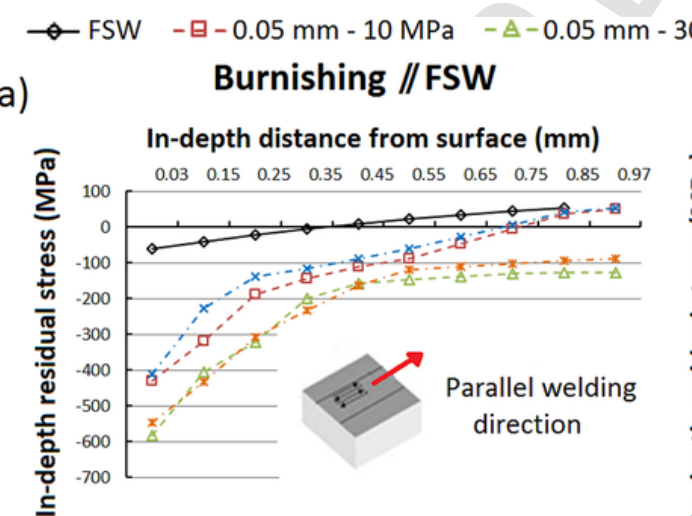

c)

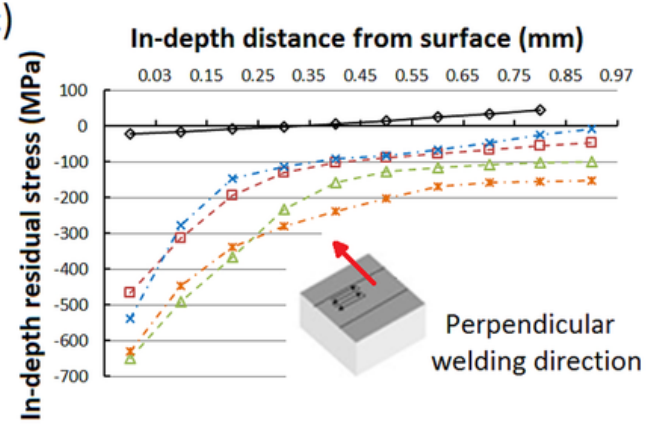

b)

$-x-0.3 \mathrm{~mm}-10 \mathrm{MPa} \quad-\mathrm{m}-0.3 \mathrm{~mm}-30 \mathrm{MPa}$

b) Burnishing $\perp$ FSW
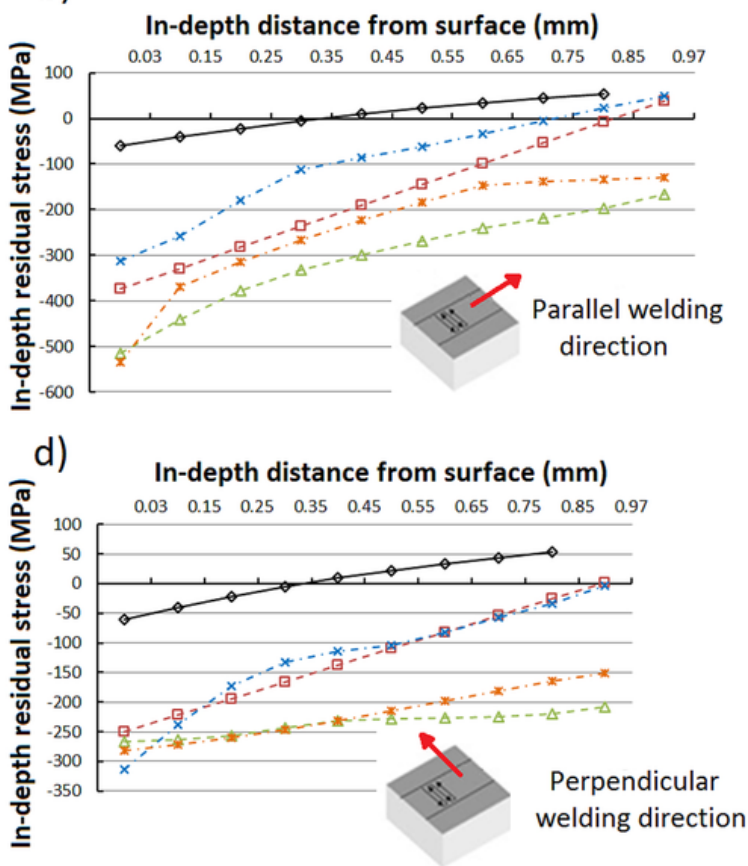

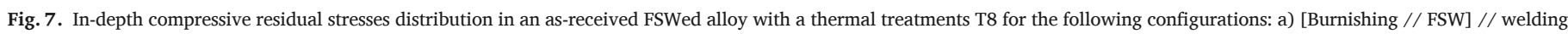
direction; b) [Burnishing // FSW] $\perp$ welding direction; c) [Burnishing $\perp$ FSW] // welding direction; b) [Burnishing $\perp$ FSW] $\perp$ welding direction. 
ing strategy is deployed to the welding direction (Fig. 7c), while the lowest measurements are found in the perpendicular direction to the burnishing trajectory (Fig. 7d). In particular, compressive stresses are found to be $-649 \mathrm{MPa}$ and $-628 \mathrm{MPa}$ for respective radial feeds of $0.05 \mathrm{~mm}$ and $0.3 \mathrm{~mm}$ and a burnishing pressure of $30 \mathrm{MPa}$. Nevertheless, a perpendicular strategy to the welding direction exhibits the lower compressive stress when the measurement is done perpendicular to the burnishing trajectory (Fig. 7d), with values within the range of $-250 \mathrm{MPa}$ and $-315 \mathrm{MPa}$ depending on the burnishing parameters. Furthermore, a similar stress distribution is found when comparing parallel and perpendicular burnishing strategies and the measurement is recorded parallel to the burnishing trajectory (Fig. 7a and b). This could be explained by the fact that the measurement is done along the welding area, so little effect is observed between the interface of the welding area and the as-received material which has not been thermally affected by the FSW. Moreover, it should be noted that compressive residual stresses are found to be below $-100 \mathrm{MPa}$ beyond of $1 \mathrm{~mm}$ of depth for those burnishing strategies deployed with a pressure of $30 \mathrm{MPa}$. Therefore, the burnishing pressure is a crucial operational parameter to achieve large compressive residual stresses at the surface and beyond $1 \mathrm{~mm}$ of depth. However, the radial feed does not show significant differences in the stress distribution when using the same pressure. Finally, the burnishing treatment enhances the compressive residual stress at least five times in the worse burnishing configuration.

\subsection{Prediction of residual stress distributions based on the radial feed configuration}

The residual stresses distribution based on the radial feeds is studied here to assess when the radial feed has no influence on the residual stress distribution. From the industrial point of view, it is interesting to reduce the time consumption of the surface treatment by increasing the radial feed during the surface treatment. It is desired to not compromise a uniform compressive residual stresses distribution at the $\mathrm{z}$ and in-plane directions, to avoid early fatigue fracture in the welded specimens. To investigate the continuity of these residual stresses along the material surface and the in-depth direction when using different radial feeds and burnishing pressures, a 2D numerical simulation of the material response during the ball-burnishing process is performed to analyze these stresses in the transversal section, as shown in Fig. 8. A similar analysis was performed by Beres et al. [16] to study the fatigue enhancement based on the in-plane residual stresses and by Rodriguez et al. [17] to analyze the influence of the process parameters, such us burnishing feed and pressure, in the specimen surface properties. Nevertheless, none of them have reported the condition of the residual stress distribution in the cross sectional area when changing the radial feed.
A multiple-pass ball indentation process is considered in the present work. The full formulation described in Celentano et al. [18], which includes large strain elastoplastic and contact models, is solved in the context of the finite element method via an in-house code extensively validated in many engineering applications. Plane strain conditions are assumed with displacement constraints located far from the burnishing zone to avoid edge effects. The domain is discretized with four-noded isoparametric finite element elements with standard Gauss integration quadrature and a B-bar technique to circumvent the plastic volumetric locking. The mesh in the region where the indenter acts needs to be fine enough in order to improve the accuracy of the results in this region where large gradients in the solution variables are expected. A mesh refinement sensitive analysis was previously carried out in order to ensure mesh-independent results. Thus, the resulting element size in the indentation region is $5 \times 5 \mu \mathrm{m}$. The physical properties used in the numerical simulation are those summarized in Table 1 . The ball is considered as a perfectly rigid body.

The strain distribution shows dissimilar conditions upon the burnishing configurations used, where the maximum values of plastic strain are found to be 0.02 and 0.06 when using burnishing pressures of 10 and $30 \mathrm{MPa}$ respectively. When comparing the configurations of two different radial feeds and a burnishing pressure of $10 \mathrm{MPa}$, Chen et al. [19] denoted that the smaller radial feed configuration exhibited continuous strain distribution and higher strain values due to the accumulative plastic strain. Conversely, Sánchez et al. [20] observed discontinuous and smaller values of strain distribution when a larger radial feed was used. Such a strain discontinuity could be critical to ensure a cold work and compressive residual stress in the surface to improve the fatigue lifespan. Moreover, the strain distribution presents larger and deeper area of maximum values when combining the small radial feed with the higher burnishing pressure. In order to study in detail the strain distribution, Fig. 9a exhibits the profile of the simulated residual stresses in the horizontal direction and measured at $150 \mu \mathrm{m}$ of depth from the surface for which the maximum stress values are developed, whereas Fig. 9b shows the residual stresses in the vertical direction. These stress values are observed in the cross sectional plane to study the influence of the radial feed on inducing a stable compressive residual stresses.

The residual stress in the horizontal direction shows that for a smaller radial feed, higher stresses are predicted, but also a higher material hardening is observed due to the accumulative plastic strain. Additionally, similar stress values are found when comparing burnishing configurations of $10 \mathrm{MPa}-0.05 \mathrm{~mm}$ and $30 \mathrm{MPa}-0.3 \mathrm{~mm}$, despite that in the second case the stress distribution is not stable along the horizontal direction. Therefore, a residual stress continuity in the cross sectional is found when a lower radial feeds are utilized independently of the two studied burnishing pressures. On the other hand, the residual stress in the vertical direction exhibits the estimated maximum stress values

\section{$0.05 \mathrm{~mm}$}

a)

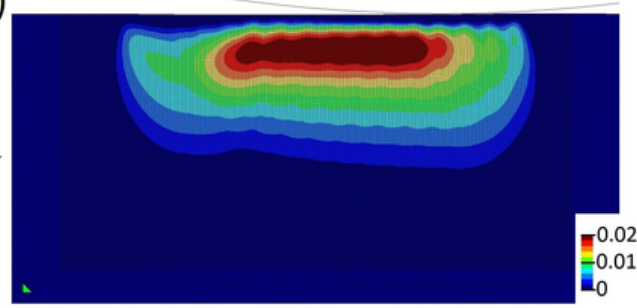

c)

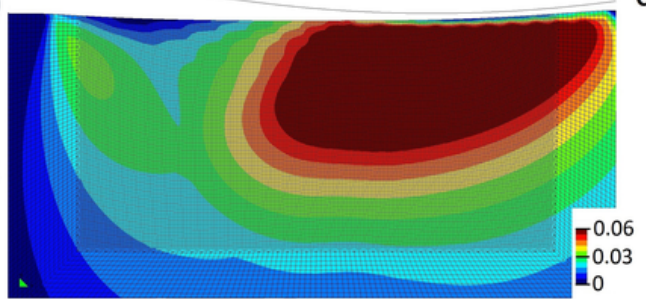

b)

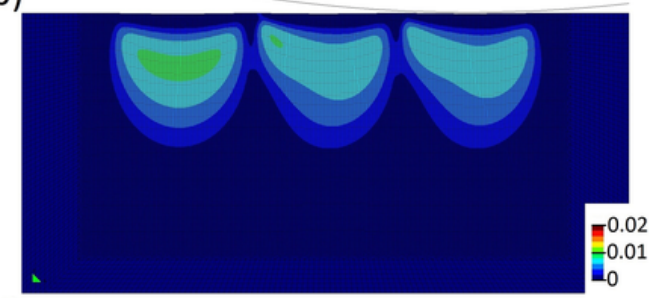

d)

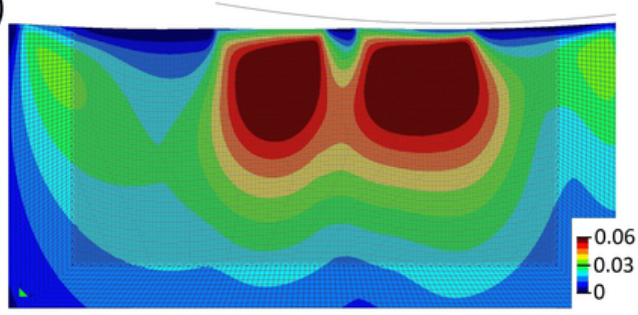

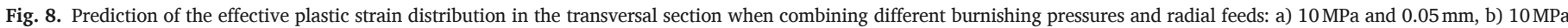
and $0.3 \mathrm{~mm}$, c) $30 \mathrm{MPa}$ and $0.05 \mathrm{~mm}$ and d) $30 \mathrm{MPa}$ and $0.3 \mathrm{~mm}$. 

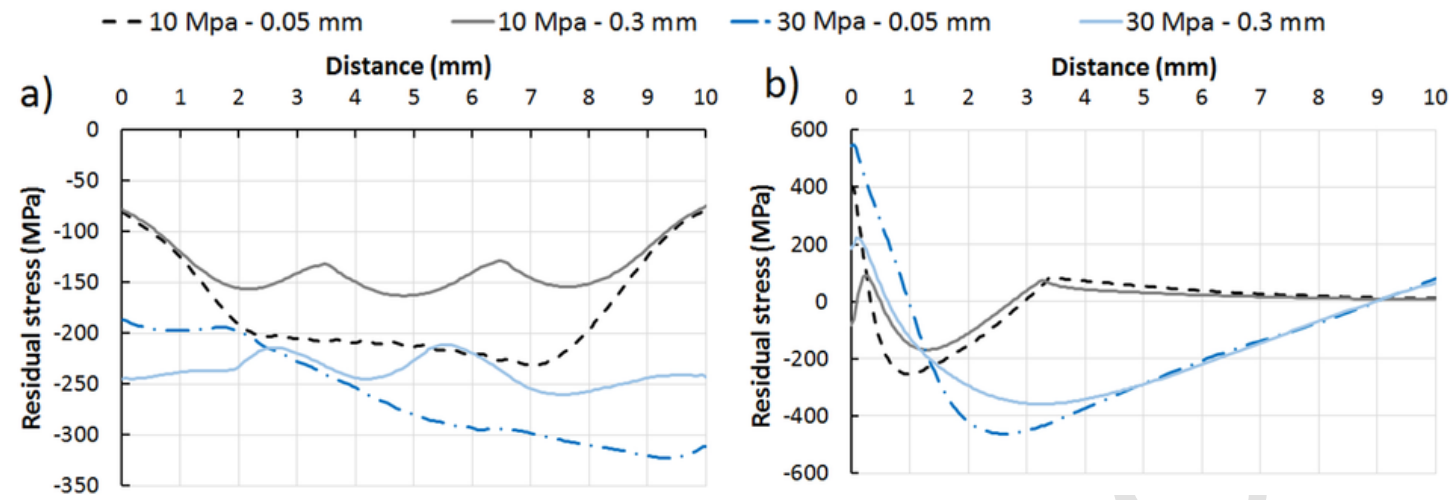

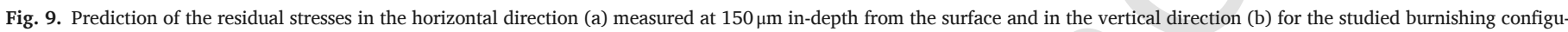
rations.

and its distribution toward the in-depth direction up to $10 \mathrm{~mm}$. Finally, the maximum values for burnishing configurations of $10 \mathrm{MPa}$ are found to be around $1 \mathrm{~mm}$ in-depth, whereas the maximum values for burnishing configurations of $30 \mathrm{MPa}$ are found to be $2.5 \mathrm{~mm}$ in-depth. The present work assumed that the maximum temperature achieved in the specimen is constant during the FSW process. It is expected that higher temperatures can be reached depending on the surface irregularities and operational parameters during the FSW process that can modify the distribution of the residual stresses due to the thermomechanical impact [21]. In short, the proper selection of the radial feed combined with the burnishing pressure is crucial to reduce time consumption during the surface treatment, but also to guarantee a good surface quality and high compressive residual stresses which are indicators of improving the lifespan of the welding area.

\section{Conclusions}

The potential benefits of combining FSW and ball-burnishing to improve the surface properties of different alloys is investigated along this manuscript. Therefore, the main findings drawn from this research can be summarized as:

- The superficial roughness has been proved to depend on the combination of strategy and operational parameters during the burnishing treatment. Accordingly, for a smaller radial pass the surface quality is better, while for a higher pressure the surface roughness gets worse due to the low hardness value of this alloy. Finally, the perpendicular strategy exhibits the best results when it is combined with a low pressure and a small radial feed.

- The pressure is the most sensitive parameter to induce compressive residual stresses in the burnished material surface. Accordingly, surface and in-depth compressive residual stresses within the range of $-300 \mathrm{MPa}$ to $-700 \mathrm{MPa}$ are achieved when combining different burnishing configurations. Those compressive residual stresses are an indicator of promoting the material lifespan under fatigue stress.

- Surface hardness increment is between $10 \%$ to $40 \%$ depending on the burnishing pressure and the pre-stress of the as-received material, whereas the radial feed does not have a noticeable influence.

- The numerical simulation confirms that the pressure is the most relevant burnishing parameter to generate compressive residual stresses in the material where more uniform stress and plastic strain profiles are obtained with the lowest radial feed.

In future work it is desired to investigate the capabilities of both FSW and ball-burnishing when joining dissimilar alloys. Such work will be very challenging due to the hardness and yield strength differences of the two targeted alloys to be firstly joined by FSW and later surface treated by ball-burnishing. It is also planned to study the structural defects, such us porosity and liquation cracking during the welding process, because they are sensitive parameters to be controlled for the joint approval of two alloys in the aeronautical industry.

\section{Acknowledgments}

This work is supported by Constellium Technology Center of France, Ministry of Economy and Competitiveness of Spain (project reference: DPI2016-74845-R) and the National Council for Scientific and Technological Development of Chile (Fondecyt Projects 3180006 and 1180591). Thanks also to Dra. Mari Luz Peñalva for the initial ideas and being the contact between companies and university.

\section{Conflicts of interest}

All the authors who sign this manuscript do not have any conflict of interest to declare. Furthermore, the corresponding author certifies that this work has not been submitted to or published in any other journal.

\section{Abbreviations}

\section{NZ Nugget zone}

T3 Solution heat treated, and naturally aged to a substantially stable condition.

T8 Solution heat treated, cold worked, then artificially aged

FSW Friction Stir Welding

$\mathrm{a}_{\mathrm{b}} \quad$ Radial feed

$\mathrm{P} \quad$ Burnishing pressure

$\sigma_{\mathrm{x}} \quad$ Residual stress in the $\mathrm{x}$-axis

$\sigma_{\mathrm{y}} \quad$ Residual stress in the y-axis

$\mathrm{R}_{\mathrm{a}} \quad$ Average roughness of a measured surface

$\mathrm{R}_{\mathrm{z}} \quad$ Maximum difference between the peak-valley of the recorded surface

\section{References}

[1] M.M. Schwartz, Metals Joining Manual, McGraw-Hill Book Co, 1979. ISBN 0070557209.

[2] Y. Bozkurt, M. Kemal Bilici, Application of Taguchi approach to optimize of FSSW parameters on joint properties of dissimilar AA2024-T3 and AA5754-H22 aluminum alloys, Mater. Des. 51 (2013) 513-521, https://doi.org/10.1016/j.matdes. 2013.04.074.

[3] R. Zettler, A.A. Monarco da Silva, S. Rodrigues, A. Blanco, J. Fernandez dos Santos, Dissimilar Al to mg alloy friction stir welds, Adv. Eng. Mater. 8 (5) (2006) 415-421, https://doi.org/10.1002/adem.200600030.

[4] D. Lohwasser, Z. Chen, Friction Stir Welding: From Basics to Applications, Elsevier, 2009. ISBN: 9781845694500.

[5] Factories of the Future: Multi Annual Roadmap for the Contractual PPP under Horizon 2020. European Commission: Unit G.2 - New Forms of Production, 2013ISBN: 978-92-79-31238-0https://doi.org/10.2777/29815.

[6] R. Cojocaru, C. Ciuca, L.N. Boţilă, V. Verbitchi, I.A. Perianu, New joining techniques for the production of the electrical components in the automotive industry, Adv. Mater. Res. 1146 (2018) 98-105, https://doi.org/10.4028/www.scientific. net/AMR.1146.98.

[7] P.S. Prevey, N. Jayarama, R.A. Ravindranath, M. Shepard, Improved high cycle fatigue damage tolerance of turbine engine compressor components by low plasticity burnishing (LPB), J. Eng. Gas Turbines Power (2004) https://doi.org/10.1115/1. 2771244.

[8] Y.X. Huang, L. Wan, S.X. Lv, Z. Zhang, H.J. Liu, New technique of in situ rolling friction stir welding, Sci. Technol. Weld. Join. 17 (8) (2012) 636-642, https://doi. org/10.1179/1362171812Y.0000000056. 
[9] L.N. López de Lacalle, A. Lamikiz, J.A. Sánchez, J.L. Arana, The effect of ball bur nishing on heat-treated steel and Inconel 718 milled surfaces, Int. J. Adv. Manuf. Technol. 32 (2007) 958-968, https://doi.org/10.1007/s00170-005-0402-5.

[10] L.N. López de Lacalle, A. Lamikiz, J. Muñoa, J.A. Sanchez, Quality improvement of ball-end milled sculptured surfaces by ball burnishing, Int J Mach Tool Manu 45 (2005) 1659-1668, https://doi.org/10.1016/j.ijmachtools.2005.03.007.

[11] D. Lohwasser, Z. Chen, Friction Stir Welding: From Basics to Applications, Elsevier, 2009. ISBN: 9781845697716.

[12] G. Wang, Y. Zhao, Y. Hao, Friction stir welding of high-strength aerospace aluminum alloy and application in rocket tank manufacturing, J. Mater. Sci. Technol. 34 (1) (2018) 73-91, https://doi.org/10.1016/j.jmst.2017.11.041.

[13] A. Rodriguez, L.N. López de Lacalle, A. Celaya, A. Fernandez, A. Lamikiz, Ball burnishing application for finishing sculptured surfaces in multi-axis machines, Int. J. Mechatron. Manuf. Syst. 4 (3/4) (2011) 220-237, https://doi.org/10.1504/IJMMS 2011.041470.

[14] A. Nestler, A. Schubert, Roller burnishing of particle reinforced aluminium matrix composites, Metals 8 (95) (2018) 1-9, https://doi.org/10.3390/met8020095.

[15] J. Scheel, P. Prevéy, D. Hornbach, Safe life conversion of aircraft aluminum structures via low plasticity burnishing for mitigation of corrosion related failures, In: Presented at Department of Defense Corrosion Conference, Washington DC, August, 2009, pp. 10-14.
[16] W. Beres, J. Li, P.C. Patnaik, Numerical simulation of the low plasticity burnishing process for fatigue property enhancement, In: Turbo Expo: Power for Land, Sea, and Air, Vol. 4: Turbo Expo, ASME, 2004, pp. 809-818, https://doi.org/10.1115/ GT2004-53925.

[17] A. Rodriguez, L.N. López de Lacalle, A. Celaya, A. Lamikiz, J. Albizuri, Surface improvement of shafts by the deep ball-burnishing technique, Surf. Coat. Technol. 206 (2012) 2817-2824, https://doi.org/10.1016/j.surfcoat.2011.11.045.

[18] D. Celentano, B. Guelorget, M. François, M. Cruchaga, A. Slimane, Numerical simulation and experimental validation of the microindentation test applied to bulk elastoplastic materials, Model. Simul. Mater. Sci. Eng. 20 (2012), 045007, (31 pages) https://doi.org/10.1088/0965-0393/20/4/045007.

[19] W. Chen, Q. Wang, F. Wang, L.M. Keer, J. Cao, Three-dimensional repeated elasto-plastic point contact, rolling and siding, ASME J. Appl. Mech. 75 (2) (2008) 1-12, https://doi.org/10.1115/1.2755171.

[20] A.J. Sánchez Egea, H.A. González Rojas, D. Celentano, J. Jorba Peiró, Mechanica and metallurgical changes on 308L wires drawn with electropulses, Mater. Des. 90 (2016) 1159-1169.

[21] A.J. Sánchez Egea, H.A. González Rojas, D. Celentano, J. Jorba Peiró, J. Cao, Thermomechanical analysis of an electrically assisted wire drawing process, J. Manuf. Sci. Eng. 139 (2017) 111017/1-111017/7, https://doi.org/10.1115/1.4037798. 